Case Reports
in Dermatology
Case Rep Dermatol 2021;13:12-17

DOI: 10.1159/000511537

Published online: January 21, 2021
(C) 2021 The Author(s)

Published by S. Karger AG, Basel www.karger.com/cde

\title{
A Diagnostically Challenging Case of Febrile Ulceronecrotic Mucha- Habermann Disease in an Adult Female Successfully Treated with Methotrexate and Cyclosporine
}

\author{
Tracy Ngo ${ }^{a}$ Claudia Hossain ${ }^{a}$ Jason Cohen $^{b}$ Beth McLellan ${ }^{a}$ \\ Rachel Blasiak $^{a} \quad E$ Eugene Balagula ${ }^{a}$ \\ aDivision of Dermatology, Department of Internal Medicine, Albert Einstein College of \\ Medicine, Bronx, NY, USA; 'bermpath Diagnostics, Port Chester, NY, USA
}

\section{Keywords}

Febrile ulceronecrotic Mucha-Habermann disease - Pityriasis lichenoides et varioliformis acuta - Pityriasis lichenoides with ulceronecrosis and hyperthermia - Methotrexate ·

Cyclosporine

\begin{abstract}
Febrile ulceronecrotic Mucha-Habermann disease (FUMHD) is a rare and severe variant of pityriasis lichenoides et varioliformis acuta (PLEVA) characterized by intermittent pyrexia, acute onset of generalized ulceronecrotic lesions, and histopathology suggestive of PLEVA. Prompt diagnosis and treatment are necessary to halt the progression of this potentially fatal disease; however, the widely variable presentation of FUMHD in addition to its rarity poses a diagnostic challenge. We report the case of a previously healthy 43 -year-old woman who presented to the emergency department with 1 month of generalized rash and intermittent fevers. Her only reported new exposure were elective intravenous vitamin infusions received at a medi-spa 1 week prior to onset of lesions. Initial evaluations were inconclusive, and confluent ulceronecrotic, hemorrhagic lesions appeared on approximately $90 \%$ of her body despite steroid, antibiotic, and cyclosporine therapy. Repeat histopathology was consistent with PLEVA, and in
\end{abstract}

\begin{tabular}{ll}
\hline & Beth McLellan \\
& Montefiore M-E Center for Cancer Care \\
& 1521 Jarrett Place, Bronx, NY 10461 (USA) \\
bmclella@montefiore.org
\end{tabular}




\section{Case Reports in Dermatology}

Case Rep Dermatol 2021;13:12-17

DOI: 10.1159/000511537

Ngo et al.: FUMHD Treated with Methotrexate

the context of her clinical presentation she was diagnosed with FUMHD. The patient rapidly attained remission with methotrexate therapy but sustained residual scarring.

(C) 2021 The Author(s)

Published by S. Karger AG, Basel

\section{Introduction}

Febrile ulceronecrotic Mucha-Habermann disease (FUMHD), also known as pityriasis lichenoides with ulceronecrosis and hyperthermia, is a rare and potentially fatal variant of pityriasis lichenoides et varioliformis acuta (PLEVA) with no established evidence-based treatment regimen [1-4]. The presentation of FUMHD is widely variable with key features being intermittent high fevers, acute onset of erythematous papules and plaques that evolve into generalized ulceronecrotic, hemorrhagic lesions, and histopathology suggestive of PLEVA [2, 5]. FUMHD tends to affect more males than females and more children than adults [2]. Diagnosing FUMHD in adults can be difficult since it is not well known, cannot be confirmed by diagnostic testing, and can mimic other diseases [2, 4]. Here, we describe a diagnostically challenging case of FUMHD in a 43-year-old female who received multiple dermatological evaluations before a diagnosis of FUMHD was confirmed and successfully treated with methotrexate and cyclosporine.

\section{Case Report}

A previously healthy 43-year-old female presented to the emergency department with a generalized rash for 1 month and intermittent fevers. The patient's only reported new exposure consisted of elective intravenous vitamin infusions consisting of glutathione, ascorbic acid, selenium, zinc, and vitamin B complex obtained at a local medi-spa approximately 1 week prior to skin eruptions. Numerous outside dermatology evaluations had been initially pursued with inconclusive biopsies and the patient had been unsuccessfully treated with topical and systemic steroids, doxycycline, cephalexin, and oral cyclosporine for presumed pustular psoriasis.

Upon transfer to our institution, the patient presented with confluent erythematous, necrotic papules and plaques with weeping extensive ulcerations and hemorrhagic crusting on her face, abdomen, extremities, and back (Fig. 1a). On her bilateral lower extremities there were violaceous papules, purpuric, umbilicated, hemorrhagic bullae, and numerous scalloped confluent ulcerations (Fig. 1b). The patient reported associated discomfort and pain. The lesions covered approximately $80 \%$ of the patient's body, including her external genitalia. There was no ocular, oral, or vaginal involvement at the time of admission. Nikolsky sign was negative.

The patient's labs showed elevated WBC $\left(10.9 \times 10^{3} / \mu \mathrm{L}\right.$; normal $\left.5-10 \times 10^{3} / \mu \mathrm{L}\right)$, electrolyte imbalance (sodium $123 \mathrm{mEq} / \mathrm{L}$, normal 136-145 mEq/L; chloride $93 \mathrm{mEq} / \mathrm{L}$, normal 95$105 \mathrm{mEq} / \mathrm{L}$ ), hypocalcemia (calcium $7.6 \mathrm{mg} / \mathrm{dL}$, normal 8.4-10.2 mg/dL), transaminitis (ALT $230 \mathrm{U} / \mathrm{L}$, normal 8-40 U/L; AST $83 \mathrm{U} / \mathrm{L}$, normal 8-40 U/L), and hypoalbuminemia (2.5 g/dL, normal 3.5-5.5 g/dL). Swabs obtained from intact vesicles and ulcerations were negative for herpes simplex virus and varicella. A wound culture of pustule was positive for many Enterobacter species, Escherichia coli, and Staphylococcus lugdunensis. Urine culture was positive for

\section{Karger'=}




\section{Case Reports in Dermatology}

Case Rep Dermatol 2021;13:12-17

DOI: 10.1159/000511537

(c) 2021 The Author(s). Published by S. Karger AG, Basel www.karger.com/cde

Ngo et al.: FUMHD Treated with Methotrexate

E. coli and Enterococcus. Blood culture showed no growth. Direct immunofluorescence performed at the same time as the original outside biopsy suspicious for pustular psoriasis was negative. Serologies were negative for HIV, hepatitis B and C, and rheumatoid factor. Flow cytometric analysis showed no evidence of lymphoproliferative disorder.

The patient was continued on cyclosporine $4 \mathrm{mg} / \mathrm{kg} /$ day twice daily and started on intravenous fluids, vancomycin, piperacillin and tazobactam, mupirocin $2 \%$ ointment twice daily to eroded areas, and triamcinolone $0.1 \%$ ointment twice daily to erythematous lesions.

Despite therapy, her lesions further evolved into confluent pustulovesicles, eroded papules, plaques, crust, hemorrhagic bullae, and macerated, eroded plaques in the axillae and inframammary regions (Fig. 2). Additionally, she developed erosions on her dorsal tongue, clitoral hood, and labia minora. Given the progression, the patient was transferred to the burn unit.

A repeat biopsy revealed interface vesicular dermatitis with epidermal necrosis which was consistent with PLEVA (Fig. 3a, b). Repeat direct immunofluorescence showed linear C3 and IgA at the basement membrane zone which was attributed to linear IgA deposits secondary to vancomycin, or more likely, nonspecific findings sometimes reported in FUMHD patients $[6,7]$.

In the context of her fever and systemic symptoms, cutaneous findings, and histopathology, a diagnosis of FUMHD was made. The patient was started on oral methotrexate $20 \mathrm{mg}$ dosed weekly, folic acid $1 \mathrm{mg}$ daily, oral doxycycline $100 \mathrm{mg}$ twice daily, levofloxacin $750 \mathrm{mg}$ daily, and ceftriaxone $1 \mathrm{~g}$ daily, and continued on oral cyclosporine $150 \mathrm{mg}$ twice daily, triamcinolone $0.1 \%$ ointment, and mupirocin $2 \%$ ointment.

Progression of lesions halted and significant peripheral re-epithelization of the erosions was observed 2 weeks after the start of methotrexate therapy. The patient was discharged with continued methotrexate, folic acid, doxycycline, cyclosporine, and triamcinolone therapy (same dosing as mentioned above). On follow-up, the disease remains in remission with continued methotrexate therapy; however, the patient has sustained significant scarring and postinflammatory pigment alteration.

\section{Discussion}

Early symptoms of FUMHD can vary between patients and as evidenced by our patient, it may take repeat skin biopsies until the correct diagnosis can be reached. Unfortunately, this delay in diagnosis and treatment may jeopardize patients' chances of recovery, as early intervention has been suggested to improve prognosis [2, 4, 6-8]. To better define this disease, Nofal et al. [2] proposed that acute onset of generalized ulceronecrotic papules and plaques associated with fever and histopathological findings consistent with PLEVA is needed to make a diagnosis of FUMHD. Through our patient's evolving disease course, our differential diagnoses included pustular psoriasis with superimposed impetiginization or herpetic lesions versus less likely pemphigus foliaceous, systemic contact, and other immunobullous disease. Given the histological diagnosis of pustular psoriasis/psoriasis, we considered acute generalized exanthematous pustulosis on the histological diagnosis, though there was no drug to suggest this. Flow cytometric analysis was used to check for lymphoproliferative disorder as FUMHD has been also known to mimic primary cutaneous aggressive epidermotropic CD8+ cytotoxic T-cell lymphoma [4]. Various treatments attempted for FUMHD include immunosuppressants, antibiotics, antivirals, phototherapy, intravenous immunoglobulin, and dapsone, but individ-

\section{Karger'=}




\section{Case Reports in Dermatology}

\begin{tabular}{l|l}
\hline Case Rep Dermatol 2021;13:12-17 \\
\hline DOI: 10.1159/000511537 & $\begin{array}{l}\text { @ 2021 The Author(s). Published by S. Karger AG, Basel } \\
\text { www.karger.com/cde }\end{array}$ \\
\hline
\end{tabular}

Ngo et al.: FUMHD Treated with Methotrexate

ual treatment efficacy is difficult to determine and largely based on anecdotal evidence from case reports $[2,5]$. In the literature, methotrexate is increasingly presented as a favorable treatment modality, although at least four fatalities have occurred despite methotrexate therapy $[2,8]$. Given its relative success, methotrexate has been suggested as first-line treatment for FUMHD, but reports have cautioned that FUMHD can recur upon discontinuation of methotrexate, and long-term methotrexate use has been linked to serious side effects including hepatoxicity and hematopoietic suppression $[9,10]$. Though diagnostic criteria have been proposed for FUMHD, no evidence-based treatment regimens have been established, presenting an area for continued research [2].

\section{Statement of Ethics}

The patient provided written informed consent to the writing of this article and the publication of pictures. The research was conducted ethically in accordance with the World Medical Association Declaration of Helsinki.

\section{Conflict of Interest Statement}

The authors have no conflicts of interests to declare.

\section{Funding Sources}

No funding was received for this case report.

\section{Author Contributions}

All authors made substantial contributions to the writing and editing of the manuscript and approved the final version. T. Ngo prepared the manuscript. C. Hossain, B. McLellan, R. Blasiak, and E. Balagula were involved in patient care and provided critical feedback during the preparation of the manuscript. J. Cohen performed the histological analyses and wrote the histological descriptions.

\section{References}

1 Bowers S, Warshaw EM. Pityriasis lichenoides and its subtypes. J Am Acad Dermatol. 2006 Oct;55(4):55772; quiz 573-6.

2 Nofal A, Assaf M, Alakad R, Amer H, Nofal E, Yosef A. Febrile ulceronecrotic Mucha-Habermann disease: proposed diagnostic criteria and therapeutic evaluation. Int J Dermatol. 2016 Jul;55(7):729-38.

3 Virdi SK, Kanwar AJ, Saikia UN. Pityriasis lichenoides with ulceronecrosis and hyperthermia: a rare variant of pityriasis lichenoides et varioliformis acuta. Indian J Dermatol Venereol Leprol. 2010 Mar-Apr;76(2):1725.

4 Lalevee S, Ortonne N, Hotz C, Schlemmer F, Beldi-Ferchiou A, Delfau-Larue MH, et al. Febrile ulceronecrotic Mucha Habermann disease mimicking aggressive epidermotropic CD8+ cytotoxic T-cell lymphoma: a diagnostic challenge. Eur J Dermatol. 2018 Dec;28(6):834-5.

\section{Karger'=}




\section{Case Reports in Dermatology}

\begin{tabular}{l|l}
\hline Case Rep Dermatol 2021;13:12-17 \\
\hline DOI: 10.1159/000511537 & $\begin{array}{l}\text { ○ 2021 The Author(s). Published by S. Karger AG, Basel } \\
\text { www.karger.com/cde }\end{array}$ \\
\hline
\end{tabular}

Ngo et al.: FUMHD Treated with Methotrexate

5 Lejuste FX, Michaux C, Lehners C, Calteux N. Febrile ulceronecrotic Mucha-Habermann disease. BMJ Case Rep. 2013 Oct;2013:bcr2013009739.

6 Lode HN, Döring P, Lauenstein P, Hoeger P, Dombrowski F, Bruns R. Febrile ulceronecrotic MuchaHabermann disease following suspected hemorrhagic chickenpox infection in a 20-month-old boy. Infection. 2015 Oct;43(5):583-8.

7 Kreuter A, Knispel S, Wieland U, Oellig F, Tigges C. Complete resolution of febrile ulceronecrotic MuchaHabermann disease following infliximab therapy. J Dtsch Dermatol Ges. 2016 Feb;14(2):184-6.

8 Griffith-Bauer K, Leitenberger SL, Krol A. Febrile Ulceronecrotic Mucha-Habermann Disease: Two Cases with Excellent Response to Methotrexate. Pediatr Dermatol. 2015 Nov-Dec;32(6):e307-8.

9 Bulur I, Kaya Erdoğan H, Nurhan Saracoglu Z, Arık D. Methotrexate Treatment in Children with Febrile Ulceronecrotic Mucha-Habermann Disease: Case Report and Literature Review. Case Rep Dermatol Med. 2015;2015:357973.

10 Cornelison RL Jr, Knox JM, Everett MA. Methotrexate for the treatment of Mucha-Habermann disease. Arch Dermatol. 1972 Oct;106(4):507-8.
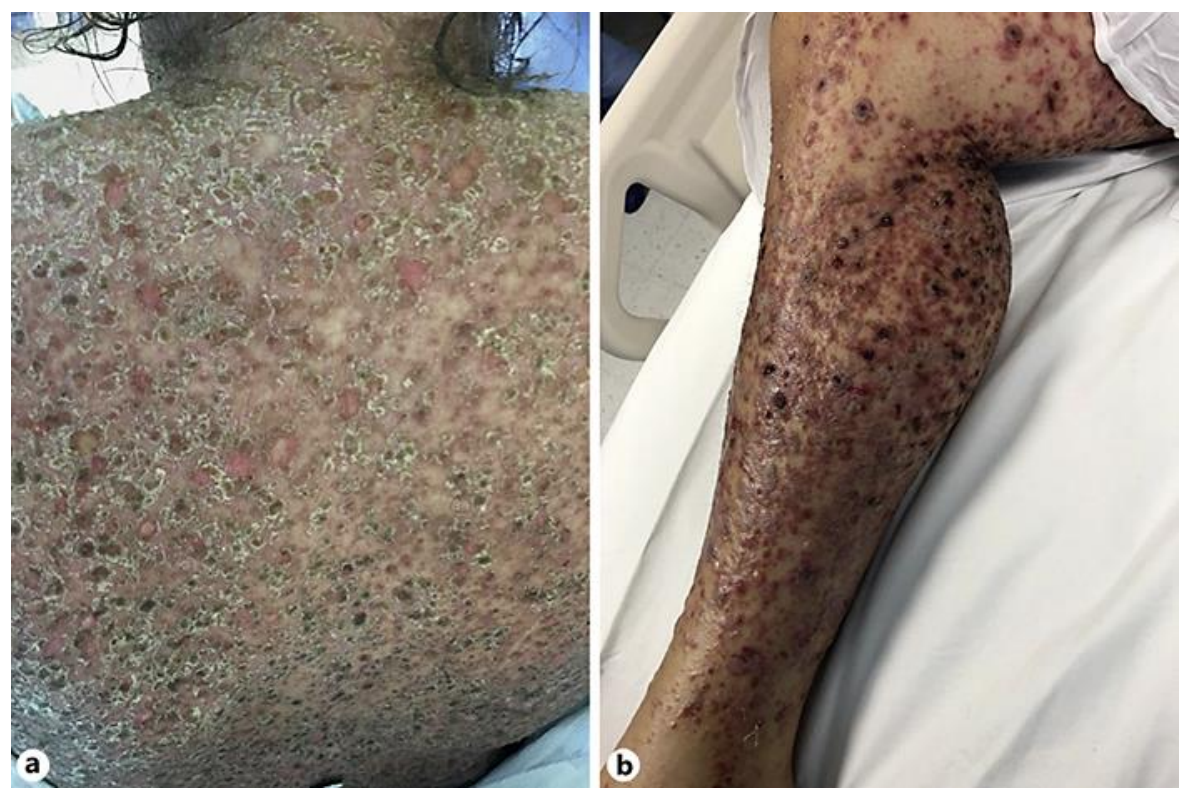

Fig. 1. a Severe, extensive, crusted papules and papulovesicles, hemorrhagic bullae, weeping erosions, and collarettes of scale on the patient's back. b Violaceous papules, purpuric, umbilicated, hemorrhagic bullae, and numerous scalloped confluent ulcerations on the patient's right leg. 


\section{Case Reports in Dermatology}

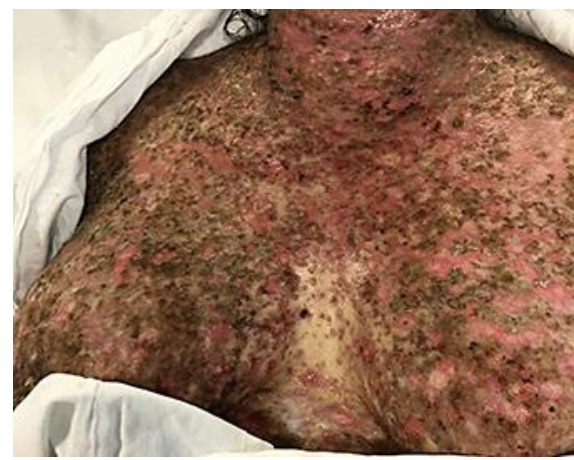

Fig. 2. Generalized vesicles and eroded papules with central necrotic crust, coalescing into plaques covering approximately $90 \%$ of the body surface area.
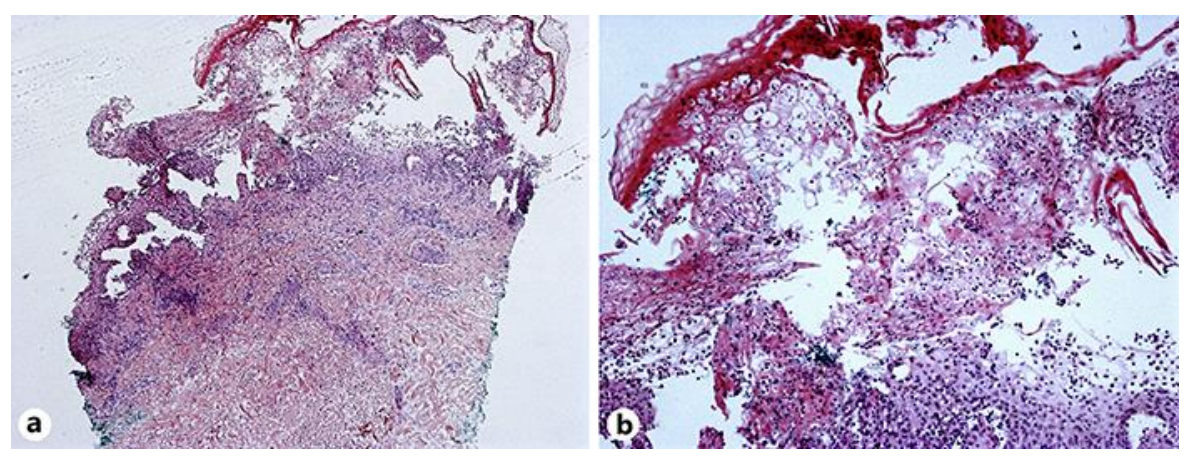

Fig. 3. Punch biopsy showing interface vesicular dermatitis with epidermal necrosis. The results are compatible with pityriasis lichenoides et varioliformis acuta. H\&E, original magnification 40× (a) and 200× (b). 